\title{
Growth and Characterization of Graphene on Polycrystalline SiC Substrate Using Heating by $\mathrm{CO}_{2}$ Laser Beam
}

\author{
Nierlly Karinni de Almeida Maribondo Galvãa ${ }^{a *}$, Getúlio de Vasconcelos ${ }^{b}$, \\ Marcos Valentim Ribeiro dos Santos ${ }^{b}$, Tiago Moreira Bastos Campos ${ }^{a}$, Rodrigo Sávio Pessoa a,c, \\ Marciel Guerino ${ }^{a}$, Mohamed Abdou Djouadid, Homero Santiago Maciela,c \\ a Technological Institute of Aeronautics, Praça Marechal Eduardo Gomes, 50, São José dos Campos, \\ 12228-900, São Paulo, SP, Brazil \\ ${ }^{b}$ Institute of Advanced Studies, Photonics Division, Rodovia dos Tamoios, 12.228-001, São Jose dos \\ Campos, SP, Brazil \\ ${ }^{c}$ Nanotecnology and Plasma Processes Laboratory, University of Paraiba Valley, 12244-000, São Jose \\ dos Campos, SP, Brazil \\ ${ }^{d}$ Institut dês Matériaux Jean Rouxel IMN, UMR 6502, Université de Nantes, 1 Quai de Tourville 44035, \\ Nantes Cedex 1, France
}

Received: April 12, 2016; Revised: July 27, 2016; Accepted: September 04, 2016

\begin{abstract}
The thermal decomposition of silicon carbide ( $\mathrm{SiC}$ ), with the subsequent formation of graphene, can be achieved by heating treatment. Several heating processes have been applied for this purpose by using $\mathrm{SiC}$, either in form of powder particles or monocrystalline substrate. In this work, instead of using an expensive commercially available $\mathrm{SiC}$ wafer, a polycrystalline $\mathrm{SiC}$ substrate was obtained, based on powder metallurgy process, in order to explore the synthesis of graphene layers on its surface by using a $\mathrm{CO}_{2}$ laser beam as heating source. Different levels of energy density (fluence) were applied and Raman spectroscopy analyses demonstrated that graphene layers were formed on the polycrystalline $\mathrm{SiC}$ surface. The ratio of the integrated intensity of the D and $\mathrm{G}$ bands, and the crystallite size were calculated. The FWHM of the 2D band peaks are in excellent agreement with the range of values found in the literature. The samples irradiated with energy density of $138.4 \mathrm{~J} / \mathrm{cm}^{2}$ presented lower concentration of defects and higher crystallite size, while the lowest FWHM was obtained for energy density of $188 \mathrm{~J} / \mathrm{cm}^{2}$. The process occurred at room conditions and no gas flow was used. The results reveal a simple and cost-effective alternative for synthesis of graphene-based structures on $\mathrm{SiC}$.
\end{abstract}

Keywords: Polycrystalline SiC; Graphene; $\mathrm{CO}_{2}$ laser heating; $\mathrm{SiC}$ thermal decomposition; Raman spectroscopy

\section{Introduction}

An allotropic form of the carbon, graphene is basically constituted by a monolayer of $\mathrm{sp}^{2}$ carbon atoms arranged in a two-dimensional hexagonal lattice ${ }^{1-3}$. Graphene is a zeroband gap semiconductor and exhibits exceptional physical properties due to its extremely high carrier mobility ${ }^{2-6}$. As a result of its remarkable properties, the graphene has been widely studied in last years. Several techniques have been used to synthesize the graphene, such as mechanical exfoliation ${ }^{1,7}$, chemical exfoliation ${ }^{8,9}$, chemical vapor deposition (CVD $)^{10,11}$, chemical reduction of graphite oxide ${ }^{12}$, growth on transition metals ${ }^{13,14}$, and thermal decomposition of $\mathrm{SiC}$, that allows to synthesize an epitaxial graphene ${ }^{15-22}$.

Several papers report the growth of epitaxial graphene on $\mathrm{SiC}$ by thermal decomposition in induction furnaces operating at vacuum or at atmospheric pressure with an inert gas flow. In such methods, the sample should achieve

*e-mail: nierlly@gmail.com temperatures sufficiently high to break the $\mathrm{Si}-\mathrm{C}$ bands at the upper crystalline layers of SiC. Therefore, $\mathrm{Si}$ atoms will be sublimated and the graphitization will be able to occur, where the $\mathrm{C}$ atoms on the top of surface are rearranged to synthesize the epitaxial graphene $e^{4,16-19}$. In order to create alternative processes, some studies have shown that the addition of a layer of "catalyst material" (such as $\mathrm{Ni}$ or $\mathrm{Co}$ ) promotes the reduction of the temperature required for $\mathrm{SiC}$ decomposition ${ }^{23-26}$. Nevertheless, despite $\mathrm{SiC}$ dissociation is promoted in this case, the $\mathrm{Si}$ sublimation does not occur; rather a chemical reaction to form a silicide phase between the catalyst material and Si happens.

Recently, some works reported the use of lasers as heating sources to obtain the epitaxial graphene on $\mathrm{SiC}$. Lee $\mathrm{S}$. et al. ${ }^{27}$ reported the growth of epitaxial graphene on $\mathrm{SiC}$ wafer through the use of a pulsed UV-laser in a vacuum chamber at approximately $10^{-6}$ Torr. Yannopoulos et al. ${ }^{28}$ reported the use of a $\mathrm{CO}_{2}$ laser with Ar gas flow, with fast heating, followed by a high cooling rate. In their process, the $\mathrm{C}$-face of $\mathrm{SiC}$ wafer was 
irradiated, but the graphene grew epitaxially at the opposite face (Si-face). It is worth noting that such process did not require either vacuum or pre-treatment. These authors suggested that graphene did not grow on the $\mathrm{C}$-face (face directly exposed to the $\mathrm{CO}_{2}$ laser beam) because the partial pressure of oxygen was significantly higher on this face in comparison with $\mathrm{Si}$ face ${ }^{28}$. The process of the graphene growth with $\mathrm{CO}_{2}$ laser in atmospheric pressure was also performed by Antonelou et al. ${ }^{29}$, aiming to obtain 3D graphene froths from SiC particles. These studies show that the use of laser as a heating source for the $\mathrm{SiC}$ thermal decomposition to produce graphene is viable and promising. It is important to highlight that an advantage of this technique is the possibility to create tracks or more complex shapes of graphene on SiC surface without need of a prior lithography. Nevertheless, the investigations of this process are in the early stages, thus more studies are desirable concerning, for example, the effect of laser energy density and morphology of the substrate surface on the formation of graphene by thermal decomposition of the $\mathrm{SiC}$.

In this context, this work presents studies about the growth and characterization of graphene layers on sintered polycrystalline $\mathrm{SiC}$ substrate by using heating by $\mathrm{CO}_{2}$ laser beam. Such investigation is even more interesting since it can bring useful information to achieve our further goal, i.e, to induce, by using laser heating, the synthesis of graphene on thin films of polycrystalline $\mathrm{SiC}$ grown by plasma sputtering technique. Besides, it allows to check the applicability of this technique to grow graphene on polycrystalline $\mathrm{SiC}$, rather than on expensive crystalline $\mathrm{SiC}$ wafer. Here, the main process parameter was the energy density applied for heating the substrate and sublimation of the Si with consequent formation of graphene layers. The produced graphene was characterized by Raman spectroscopy and field emission scanning electron microscopy (FESEM). The whole process was performed under a stagnant atmospheric environment and heating and cooling occurred at standard conditions.

\section{Experimental}

\subsection{SiC samples preparation}

SiC substrates were produced by powder metallurgy technique. $\beta$-SiC powder GRADE BF-12 type from C. Hermann Starck (HCST) was used. For liquid phase sintering, different additives were added to the powder mixture: YAG (Yttrium Aluminium Garent) - $7.6 \%$ by mass, the PVA binder (polyvinyl alcohol), manufactured by VETEC Química Fina do Brasil, and Bio de flocculant Denvercril 300 produced by DENVER Resinas. For compression, an uniaxial pressing at a load of $40 \mathrm{MPa}$ and an isostatic pressing at a load of $300 \mathrm{MPa}$ were applied. The $\mathrm{SiC}$ samples were sintered at $1900^{\circ} \mathrm{C}$ in argon atmosphere, as described in the literature ${ }^{30}$.

\subsection{Si sublimation by $\mathrm{CO}_{2}$ laser heating}

The heating of the samples was performed through the use of $\mathrm{CO}_{2}$ laser beam (Synrad Evolution - 125) with 125 $\mathrm{W}$ and beam diameter of $200 \mu \mathrm{m}$, which emits infrared laser radiation in the $10.6 \mu \mathrm{m}$ wavelength band. The samples were positioned at the focal region of the laser, as illustrated in Figure 1. For all samples, $100 \%$ of the laser power and a beam overlap of $50 \%$ were used. Nevertheless, in order to change the energy density applied to the samples, different scanning velocities of the laser beam were used. Table 1 shows each scanning velocity used and the correspondent energy density.

\subsection{Material characterization}

Raman spectroscopy measurements were performed using a Renishaw system model 2000 equipped with an Ar ion laser $(514.5 \mathrm{~nm})$. Raman spectra were obtained at room temperature in the range of 450 to $2800 \mathrm{~cm}^{-1}$ for analyses of the $\mathrm{SiC}$ substrate and 1200 to $1700 \mathrm{~cm}^{-1}$ and 2400 to 2900 $\mathrm{cm}^{-1}$ for the graphene. For more accurate results, the baseline of each spectrum was subtracted to highlight the areas and intensities of the peaks.

Many authors have shown that it is possible to obtain from Raman analysis the inherent features of the graphene, including structural quality and the number of layers ${ }^{23,31-33}$. Raman spectra obtained by laser excitation at $2.41 \mathrm{eV}$ have shown that the $\mathrm{G}$ and 2D bands, which appear at approximately $1582 \mathrm{~cm}^{-1}$ and $2700 \mathrm{~cm}^{-1}$, respectively, are the main features of a monolayer graphene ${ }^{31}$. The $\mathrm{G}$ band is associated with the $\mathrm{E}_{2 \mathrm{~g}}$ phonon mode at the Brillouin zone center, and this band originated from the first order Raman Scattering. The $2 \mathrm{D}$ band is originated from second-order, which involves the two Brillouin zone boundaries ${ }^{23,31}$. In some cases, the $\mathrm{D}$ band at $\sim 1350 \mathrm{~cm}^{-1}$ and the less intensive peaks of the D' band at $\sim 1620$ 'also appear. This D and D'-bands comes from double-resonant processes and they are related to the presence of defects and structural disorder in graphene ${ }^{31,32}$. Therefore, the relative integrated intensity (area) ratio of the $\mathrm{D}$ and $\mathrm{G}$ bands, $\mathrm{A}(\mathrm{D}) / \mathrm{A}(G)$, in some works presented as $\mathrm{I}_{\mathrm{D}} / \mathrm{I}_{\mathrm{G}}$, is used to evaluate the defect concentration of the graphene films ${ }^{25}$. From the $\mathrm{A}(\mathrm{D}) / \mathrm{A}(\mathrm{G})$ ratio, it is possible to determine the cristallite size, $L_{a}$, by using Eq.1,

$$
L_{a}(\mathrm{~nm})=\frac{560}{\mathrm{E}_{1}^{4}}\left(\frac{A(D)}{A(G)}\right)^{-1}
$$

where $\mathrm{E}_{1}$ is the excitation laser energy of Raman, in $\mathrm{eV}^{33}$.

The surface morphology of the $\mathrm{SiC}$ substrate, as well as of its surface coated with the produced graphene, was examined by using Field Emission Scanning Electron Microscopy -FESEM (Mira 3 from Tescan). 


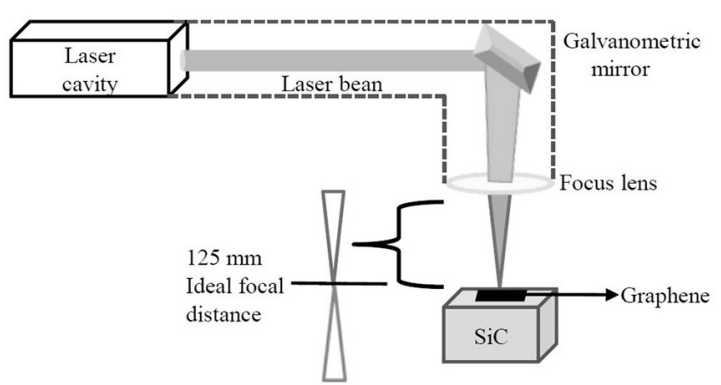

Figure 1: Schematic diagram of the laser irradiation process. During the process, the samples were positioned at the focal distance of $125 \mathrm{~mm}$.

\section{Results}

Figure 2 shows the X-Ray Diffraction (XRD) and Raman spectra of the sintered polycrystalline $\mathrm{SiC}$. The XRD spectra, Figure 2(a), showed a characteristic spectrum of $\mathrm{SiC}$ with major peaks at (111), (220), (311) and (200) respectively. For the Raman spectra, Figure 2(b), peaks referent to the Si-C band appear at $\sim 796$ and $970 \mathrm{~cm}^{-1}$. The peaks overlapping the $\mathrm{C}-\mathrm{C}$ band $(\mathrm{G}$ and $\mathrm{D}$ ) and the second order Raman spectra of the $\mathrm{SiC}$ also appear at regions $\sim 1315-1362 \mathrm{~cm}^{-1}$ and $1524-$ $1574 \mathrm{~cm}^{-1}$. However, the peaks referent to the $\mathrm{C}$ band are broad and not well defined. Peaks related to $2 \mathrm{D}$ band (2700 $\mathrm{cm}^{-1}$ ) were not observed.

Figure 3 presents the Raman spectra of graphene synthesized on the polycrystalline $\mathrm{SiC}$ for different values of energy density. The peaks of the fundamental vibration modes of graphene, D and $\mathrm{G}$ bands, and 2D band appear at $\sim 1355,1581-1607$, and $\sim 2709 \mathrm{~cm}^{-1}$, respectively. Unlike reported in some studies where $\mathrm{SiC}$ (0001) was used as a substrate, the Raman spectra obtained in the present work did not show any interference signals from SiC. Possibly this is related to the polycrystalline $\mathrm{SiC}$ used. Figure 3 clearly shows that there is no overlapping of the peaks of $\mathrm{SiC}$ and $\mathrm{C}$ bands in any of the results. The $\mathrm{D}$ and $\mathrm{G}$ band peaks are well defined, showing that, although the process has been done at room conditions, the graphene oxide is absent. By considering the vapor-emitting surface effect described by Schiller et al. ${ }^{34}$, it is possible to conclude that, in the present process, it is unlikely that the graphene suffers oxidation. When $\mathrm{Si}$ is removed from the system, the Si vapor stream drags out the present gas (atmospheric air) surrounding the material surface, what prevents the contact of the oxygen with the carbon atoms of the $\mathrm{SiC}$ surface. Also, for oxidation process to occur, it requires the effective collision between the sublimed $\mathrm{Si}$ and oxygen in the air. Therefore, due to the drag and the fact that the process happens in a short period of time, the resulting $\mathrm{C}$ in surface comes back to room temperature and there is not enough energy for the carbon oxidation reaction to occur. Also in Figure 3, the D band, which is representative of disorder and/or defects, was systematically observed. Unlike the graphene obtained by micromechanical cleavage from Highly Ordered Pyrolytic Graphite (HOPG), the graphene grown from crystalline $\mathrm{SiC}$ usually has defects (D-band) 22,23,35,36. Because polycrystalline $\mathrm{SiC}$ was used in the present work for graphene growth, the presence of defects was expected. The defect concentration, A(D)/A(G), and the cristallite sizes, $L_{a}$, are presented in Figure 4. Eckmann et al. ${ }^{37}$ investigated differents types of graphene defects by mean of Raman spectroscopy. A relation between the ratio of the peaks intensity (peaks height) D and D', I(D)/I(D'), and the type of defects in graphene was proposed: I(D)/I(D') is maximum $(\sim 13)$ for sp3-defects, $(\sim 7)$ for vacancy-like defects and, $(\sim 3.5)$ for boundaries defects. In our samples we obtained I(D)/I(D') ratios of $\sim 1.7$ and $\sim 3.61$, for samples irradiated with energy density of $200 \mathrm{~J} / \mathrm{cm}^{2}$ and $138.4 \mathrm{~J} / \mathrm{cm}^{2}$, respectively, indicating a high concentrations of boundaries defects. Also, as pointed out in Eckmann et al. ${ }^{37}$, when a graphene sample has high concentration of defects, the D' peak is somehow merged with the G peak, which is observed in our samples. Therefore, to obtain the correct height of both peaks a Lorentzian double peaks function was applied to the data.

As shown in Figure 4, only a slight increase in defect concentration could be seen when the polycrystalline $\mathrm{SiC}$ was irradiated from $138.4 \mathrm{~J} / \mathrm{cm}^{2}$ to $188.0 \mathrm{~J} / \mathrm{cm}^{2}$. Accordingly, calculated $L_{a}$ decreases from $61,48 \mathrm{~nm}$ to $41,5 \mathrm{~nm}$ when the polycrystalline $\mathrm{SiC}$ was irradiated from $138.4 \mathrm{~J} / \mathrm{cm}^{2}$ to 188.0 $\mathrm{J} / \mathrm{cm}^{2}$. As previously commented, $L_{a}$ represents the crystallite size of the graphene regions, which depends on the defect concentration. However, for $L_{a}$ analysis, it is also important to consider the influence of the morphology of the $\mathrm{SiC}$ substrate surface. The graphene produced appears as small "islands" and not as a continuous large layer, as shown in the FESEM images, Figure 4. Probably due to the non-uniform structure of the uppermost layer of the polycrystalline $\mathrm{SiC}$ and to the presence of pores, as illustrated in Figure 4(a), the extension of the formed graphene layers is limited, producing a noncontinuous coating over the substrate surface.

It is worth mentioning that the heat transfer along and across the heterogeneous surface, as in the present case, may cause non-uniformity of temperature distribution on the surface, which is another factor that may influence the thermal dissociation of $\mathrm{SiC}$, so affecting locally the graphene formation. Furthermore, the terminations of the $\mathrm{SiC}$ grains may be another source of defect concentration for the graphene islands, influencing the $L_{a}$ values. Therefore, the laser fluence may not be the only factor responsible for the

Table 1: Scanning velocities and energy applied at the samples.

\begin{tabular}{lccccccc}
\hline Scanning velocities $(\mathrm{mm} / \mathrm{s})$ & 800 & 850 & 900 & 950 & 1000 & 1150 \\
\hline Energy density $\left(\mathrm{J} / \mathrm{cm}^{2}\right)$ & 200.0 & 188.0 & 177.6 & 168.0 & 160.0 & 138.4 & 132.8 \\
\hline
\end{tabular}




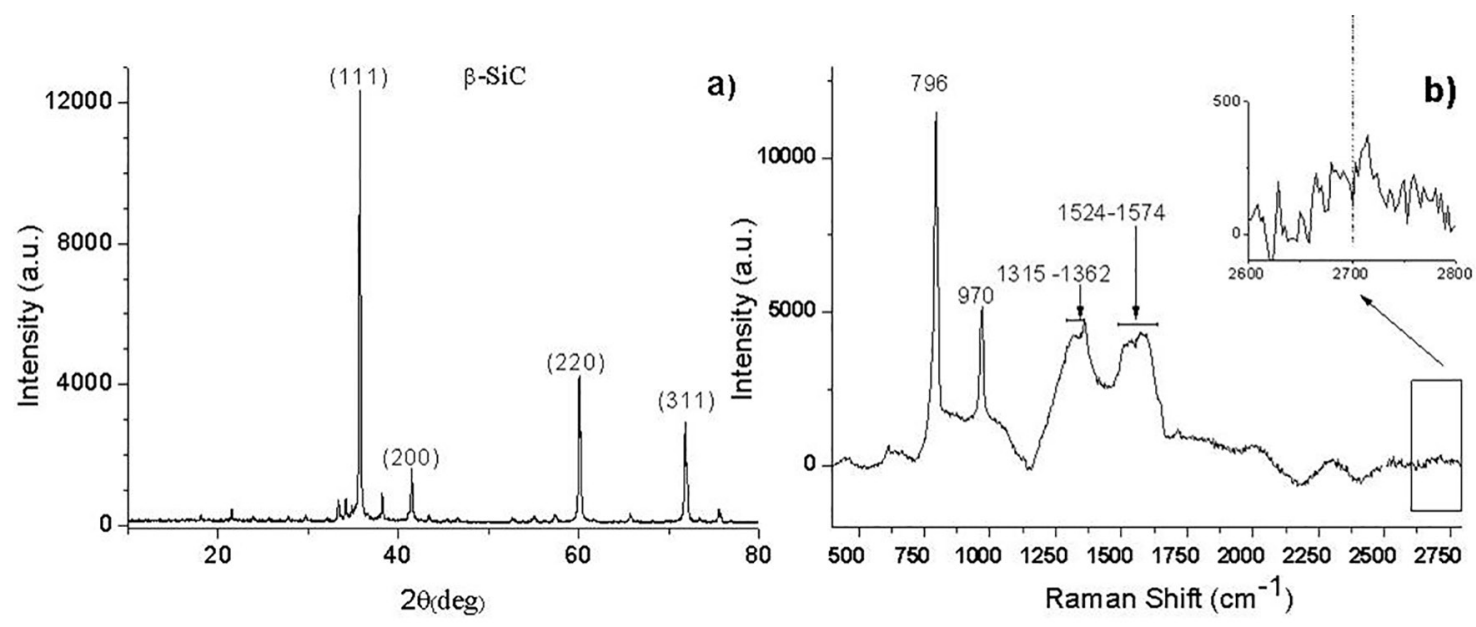

Figure 2: (a) X-ray diffraction spectra of SiC sintered; (b) Raman spectra of the polycrystalline SiC substrate.

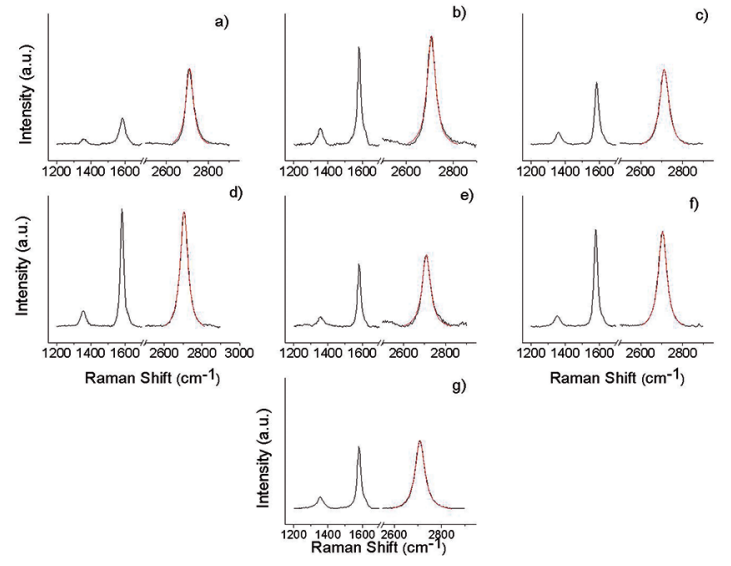

Figure 3: (color online) Raman spectra of graphene grown on $\mathrm{SiC}$ for different condition of energy density applied at the samples during laser irradiation. a) $200.0 \mathrm{~J} / \mathrm{cm}^{2}$, b) $188.0 \mathrm{~J} / \mathrm{cm}^{2}$, c) $177.6 \mathrm{~J} /$ $\mathrm{cm}^{2}$, d) $168.0 \mathrm{~J} / \mathrm{cm}^{2}$, e) $160.0 \mathrm{~J} / \mathrm{cm}^{2}$, f) $138.4 \mathrm{~J} / \mathrm{cm}^{2}$, and g) $132.8 \mathrm{~J} /$ $\mathrm{cm}^{2}$. The black line represents the experimental results and the red line the 2D band peak fitted by Lorentz function.

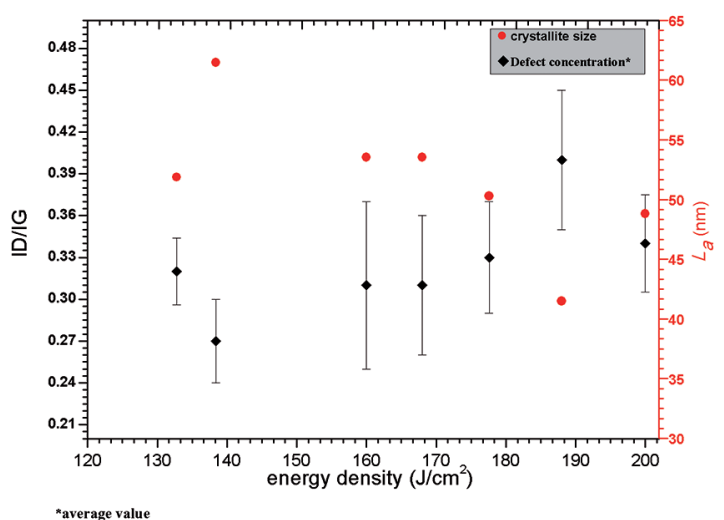

Figure 4: Relation between defect concentration, $A(D) / A(G)$, and the crystallite sizes, $L_{a}$, with the laser energy density applied for synthesis of the graphene. discrepancy between the conditions with lowest and highest concentration of defects, i.e, the polycrystalline structure also affects the defect concentration of formed graphene and, therefore, the $L_{a}$ value.

Figure 5(a) shows the surface of the untreated polycrystalline $\mathrm{SiC}$ substrate. In Figure 5(b), small graphene islands on $\mathrm{SiC}$ grains can also be seen. When the FESEM resolution was increased, it was possible to see more precisely the graphene shape, as shown in Figure 5(c). These FESEM images were obtained for the sample that presented the highest $L_{a}$ (irradiated with energy density of $138.4 \mathrm{~J} / \mathrm{cm}^{2}$ ). Is possible to see in Figure 5 (c) that the size of the grains is comparable with the $L_{a}$ calculated, including errors bars.

FWHM was obtained from the Lorentz fitting of the 2D band peak, from which the number of graphene layers can be inferred. As reported in literature, for a monolayer graphene, obtained by mechanical exfoliation, the FWHM was lower than $30 \mathrm{~cm}^{-131,38}$. Using a Raman laser of $488 \mathrm{~nm}$, Lee D.S et al. ${ }^{38}$ reported that due to the intrinsic disorder of the monolayer epitaxial graphene (grown on a Si terminated face of $\mathrm{SiC}$ ), the FWHM was found at approximately $46 \mathrm{~cm}^{-1}$, which is higher than that for exfoliated graphene. Lee D.S. et al. ${ }^{38}$ also reported results for the bi- and tri-layer graphene that exhibit a FWHM at approximately $64 \mathrm{~cm}^{-1}$ and $74 \mathrm{~cm}^{-1}$, respectively. The FWHM of the graphene obtained in our process was found in the range between $43.5 \mathrm{~cm}^{-1}$ and 49.5 $\mathrm{cm}^{-1}$. Although the results are close to those found for the monolayer epitaxial graphene, it is not possible to conclude that there is only one monolayer, since the FWHM depends on several factors such as strain, doping, point defects, heterogeneities, grain size, and stacking order ${ }^{39,40,41}$.

\section{Conclusion}

Polycrystalline $\mathrm{SiC}$ substrate was used for the first time to synthesize graphene by means of thermal decomposition 

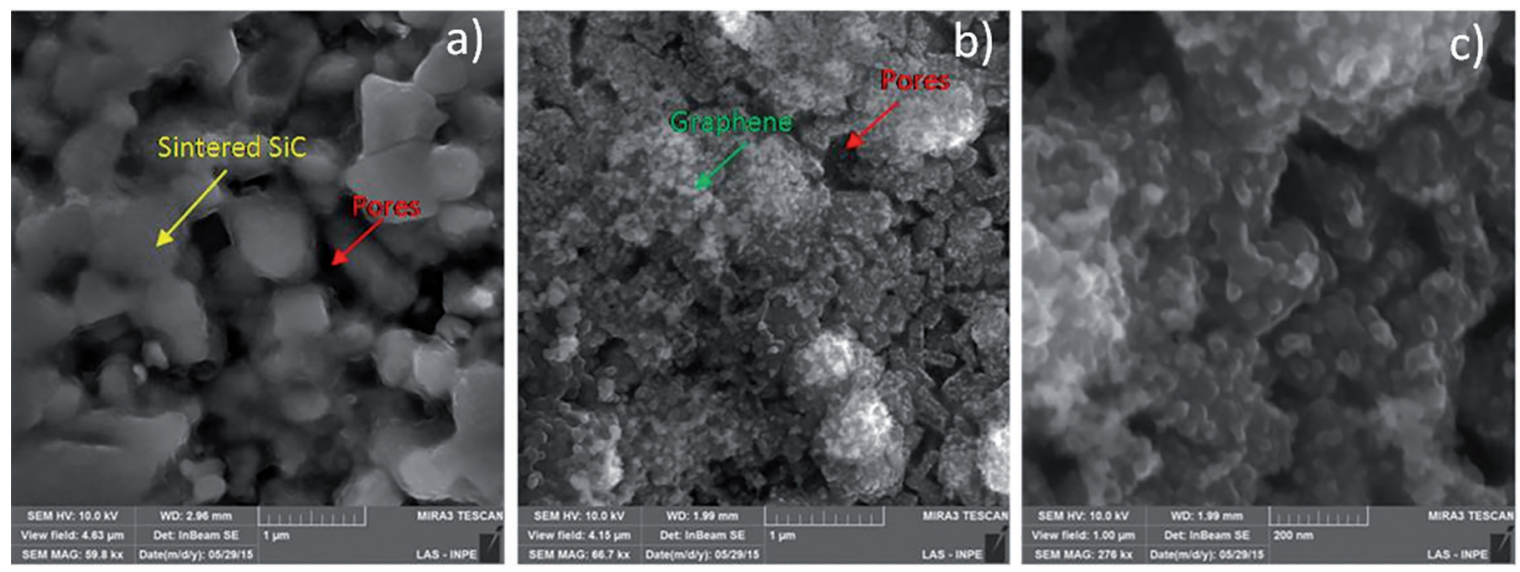

Figure 5: (color online) FESEM images: a) polycrystalline $\mathrm{SiC}$ substrate; b), and c) graphene synthesized with energy dose of $138.4 \mathrm{~J} / \mathrm{cm}^{2}$.

process using $\mathrm{CO}_{2}$ laser beam as heating source. Raman spectroscopy proved that graphene was formed on the surface of the porous and non-oriented SiC substrate. FESEM images confirm these results and show that graphene layers appear as small "islands" on top of SiC grains, spread all over the substrate surface, and not as a continuous layer as usually happens in the case of monocrystalline SiC. Graphene, free of oxidation, was synthesized for all tested conditions of laser energy density with no significant difference in the obtained material features. Such results demonstrate that the $\mathrm{CO}_{2}$ laser heating treatment, of low cost sintered $\mathrm{SiC}$, is a handy and cost-effective alternative process for coating polycrystalline $\mathrm{SiC}$ with graphene based nanostructures, which could be interesting for applications in different areas as, for example, solid lubricants in the field of nanotribology.

\section{Acknowledgements}

This work was supported by the Brazilian funding agency CAPES, grants No. 23038.005802/2014-98 and No. 88881.064970/2014-01, CNPq, grants No 4730432012, and São Paulo Research Foundation (FAPESP), grant No. 2011/07468-2 and (FAPESP/CNPq/PRONEX) No. 2011/50773-0. We also would like to thanks to the Prof. Dr. Stanislav Moshkalev for the assistance, LAS-IMPE for RAMAN measurements, and Maria Lucia Brison - LASINPE, for the FESEM images.

\section{References}

1. Novoselov KS. Nobel Lecture: Graphene: Materials in the flatland. Reviews of Modern Physics. 2011;83(3):837-849.

2. Novoselov KS, Geim AK, Morozoy SV, Jiang D, Zhang Y, Dubonos $\mathrm{SV}$, et al. Electric field effect in atomically thin carbon films. Science. 2004;306(5696):666-669.

3. Geim AK, Novoselov KS. The rise of graphene. Nature Materials. 2007;6:183-191.
4. Avouris P, Dimitrakopoulos C. Graphene: synthesis and application. Materials Today. 2012;15(3):86-97.

5. Yechika Y. Application of graphene to high-speed transistors: expectations and challenges. Science \& Technology Trends. 2010;37:76-92.

6. Huang X, Yin Z, Wu S, Qi X, He Q, Zhang Q, et al. Graphenebased materials: synthesis, characterization, properties, and applications. Small. 2011;7(14):1876-1902.

7. Tang Q, Zhou Z. Graphene-analogous low-dimensional materials. Progress in Materials Science. 2013;58(8):1244-1315.

8. Lotya M, Hernandez Y, King PJ, Smith RJ, Nicolosi V, Karlsson LS, et al. Liquid phase production of graphene by exfoliation of graphite in surfactant/water solutions. Journal of the American Chemical Society. 2009;131(10):3611-3620.

9. Khan U, O’Neill A, Lotya M, De S, Coleman JN. High-concentration solvent exfoliation of graphene. Small. 2010;6(7):864-871.

10. Qi JL, Zheng WT, Zheng XH, Wang X, Tian HW. Relatively low temperature synthesis of graphene by radio frequency plasma enhanced chemical vapor deposition. Applied Surface Science. 2011;257(15):6531-6534.

11. Choi T, Jung H, Lee CW, Mun KY, Kim SH, Park J, et al. Growth characteristics of graphene synthesized via chemical vapor deposition using carbon tetrabromide precursor. Applied Surface Science. 2015;343:128-132.

12. Dao TD, Jeong HM. Graphene prepared by thermal reductionexfoliation of graphite oxide: Effect of raw graphite particle size on the properties of graphite oxide and graphene. Materials Research Bulletin. 2015;70:651-657.

13. Batzill M. The surface science of graphene: Metal interfaces, CVD synthesis, nanoribbons, chemical modifications, and defects. Surface Science Reports. 2012;67(3-4):83-115.

14. Grandthyll S, Gsell S, Weinl M, Schreck M, Hüfner S, Müller F. Epitaxial growth of graphene on transition metal surfaces: chemical vapor deposition versus liquid phase deposition. Journal of Physics: Condensed Matter. 2012;24(31):314204.

15. Trabelsi ABG, Ouerghi A, Kusmartseva OE, Kusmartsev FV, Oueslati M. Raman spectroscopy of four epitaxial graphene layers: Macro-island grown on $4 \mathrm{H}-\mathrm{SiC}_{(0001)}$ substrate and an associated strain distribution. Thin Solid Films. 2013;539:377-383. 
16. Gupta B, Notarianni M, Mishra N, Shafiei M, Iacopi F, Motta N. Evolution of epitaxial graphene layers on $3 \mathrm{C} \mathrm{SiC} / \mathrm{Si}$ (111) as a function of annealing temperature in UHV. Carbon. 2014;68:563-572.

17. Tang J, Kang CY, Li LM, Pan HB, Yan WS, Wei SQ, et al. Graphene grown on sapphire surface by using $\mathrm{SiC}$ buffer layer with SSMBE. Physics Procedia. 2012;32:880-884.

18. Heer WA, Berger C, Wu X, First PN, Conrad EH, LI X, et al. Epitaxial graphene. Solid State Comunications. 2007;143(12):92-100.

19. Röhrl H, Hundhausen M, Emtsev KV, Seyller Th, Graupner $\mathrm{R}$, Ley L. Raman spectra of epitaxial graphene on $\mathrm{SiC}(0001)$. Applied Physics Letters. 2008;92:201918.

20. Seyller T. Epitaxial Graphene on $\mathrm{SiC}(0001)$. In: Raza H, ed. Graphene Nanoelectronics: Metrology, Synthesis, Properties and Applications. Berlin: Springer-Verlag; 2012. p. 135-145.

21. Yakimova R, Iakimov T, Yazdi GR, Bouhafs C, Eriksson J, Zakharov A, et al. Morphological and electronic properties of epitaxial graphene on SiC. Physica B: Condensed Matter. 2014;439:54-59.

22. Zhang R, Li H, Zhang ZD, Wang ZS, Zhou SY, Wang Z, et al. Graphene synthesis on $\mathrm{SiC}$ : Reduced graphitization temperature by C-cluster and Ar-ion implantation. Nuclear Instruments and Methods in Physics Research Section B: Beam Interactions with Materials and Atoms. 2015;356-357:99-102.

23. Macháč P, Fidler T, Cichoň S, Mišková L. Synthesis of graphene on $\mathrm{SiC}$ substrate via Ni-silicidation reactions. Thin Solid Films. 2012;520(16):5215-5218.

24. Macháč $\mathrm{P}$, Cichoň S, Mišková L, Vondráček M. Graphene preparation by annealing of $\mathrm{Co} / \mathrm{SiC}$ structure. Applied Surface Science. 2014;320:544-551.

25. Escobedo-Cousin E, Vassilevski K, Hopf T, Wright N, O’Neill A, Horsfall A, et al. Local solid phase growth of few-layer graphene on silicon carbide from nickel silicide supersaturated with carbon. Journal of Applied Physics. 2013;113(11):114309.

26. Li C, Li D, Yang J, Zeng X, Yuan W. Preparation of Singleand Few-Layer Graphene Sheets Using Co Deposition on SiC Substrate. Journal of Nanomaterials. 2011;2011:319624.

27. Lee S, Toney MF, Ko W, Randel JC, Jung HJ, Munakata K, et al. Laser-Synthesized Epitaxial Graphene. ACS Nano. 2010;4(12):7524-7530.

28. Yannopoulos SN, Siokou A, Nasikas NK, Dracopoulos V, Ravani F, Papatheodorou GN. CO $\mathrm{CO}_{2}$-Laser-Induced Growth of Epitaxial Graphene on 6H-SiC(0001). Advanced Functional Materials. 2012;22(1):113-120.
29. Antonelou A, Dracopoulos V, Yannopoulos SN. Laser processing of SiC: From graphene-coated $\mathrm{SiC}$ particles to 3D graphene froths. Carbon. 2015;85:176-184.

30. Abdalla AJ, Damião AJ, Campos E, Santana JGA, Vicentini MC, Trevisan TA, et al. Development of Silicon Carbide Substrates for Aerospace Applications. MRS Proceedings. 2012;1373:31-36.

31. Malard LM, Pimenta MA, Dresselhaus G, Dresselhaus MS. Raman spectroscopy in graphene. Physics Reports. 2009;473(5-6):51-87.

32. Pimenta MA, Dresselhaus G, Dresselhaus MS, Cançado LG, Jorio A, Saito R. Studying disorder in graphite-based systems by Raman spectroscopy. Physical Chemistry Chemical Physics. 2007;9(11):1276-1291.

33. Cançado LG, Takai K, Enoki T, Endo M, Kim YA, Mizusaki H, et al. General equation for the determination of the crystallite size $L_{a}$ of nanographite by Raman spectroscopy. Applied Physics Letters. 2006;88(16):163106.

34. Schiller S, Heisig U, Panzer S. Eletron Beam Technology. New York: John Wiley \& Sons; 1982.

35. Ni ZH, Chen W, Fan XF, Kuo JL, Yu T, Wee ATS, et al. Raman spectroscopy of epitaxial graphene on a SiC substrate. Physical Review B. 2008;77(11):115416.

36. Hao Y, Wang Y, Wang L, Ni Z, Wang Z, Wang R, et al. Probing layer number and stacking order of few-layer graphene by Raman spectroscopy. Small. 2010;6(2):195-200.

37. Eckmann A, Felten A, Mishchenko A, Britnell L, Krupke R, Novoselov KS, et al. Probing the Nature of Defects in Graphene by Raman Spectroscopy. Nano Letters. 2012;12(8):3925-3930.

38. Lee DS, Riedl C, Krauss B, von Klitzing K, Starke U, Smet JH. Raman Spectra of Epitaxial Graphene on $\mathrm{SiC}$ and of Epitaxial Graphene Transferred to $\mathrm{SiO}_{2}$. Nano Letters. 2008;8(12):4320-4325.

39. Tiberj A, Camara N, Godignon P, Camassel J. Micro-Raman and micro-transmission imaging of epitaxial graphene grown on the $\mathrm{Si}$ and $\mathrm{C}$ faces of $6 \mathrm{H}-\mathrm{SiC}$. Nanoscale Research Letters. 2011;6:478.

40. Kumar B, Baraket M, Paillet M, Huntzinger JR, Tiberj A, Jansen AGM, et al. Growth protocols and characterization of epitaxial graphene on $\mathrm{SiC}$ elaborated in a graphite enclosure. Physica E: Low-dimensional Systems and Nanostructures. 2016;75:7-14

41. Cançado LG, Jorio A, Pimenta MA. Measuring the absolute Raman cross section of nanographites as a function of laser energy and crystallite size. Physical Review $B$. 2007;76(6):064304. 